Article

\title{
An Assessment of Technological Innovation Capabilities of Carbon Capture and Storage Technology Based on Patent Analysis: A Comparative Study between China and the United States
}

\author{
Hong-Hua Qiu ${ }^{1,2, *(1)}$ and Jing Yang ${ }^{3}$ \\ 1 School of Law, Northwest University, Xi'an 710127, Shaanxi Province, China \\ 2 Max Planck Institute for Innovation and Competition, Marstallplaz 1, 80539 Munich, Germany \\ 3 Shanghai International College of Intellectual Property, Tongji University, Shanghai 200029, China; \\ 1731787@tongji.edu.cn \\ * Correspondence: qiuhonghua@nwu.edu.cn
}

Received: 21 January 2018; Accepted: 15 March 2018; Published: 19 March 2018

\begin{abstract}
Carbon Capture and Storage (CCS) technology is an effective technical means for addressing climate change. The patent documents related to CCS technology filed in China and the United States (U.S.) were searched from INNOGRAPHY, a business database of intellectual property and the technological innovation capabilities of CCS technology were investigated from the perspectives of the lifespan of a patent, the number of claims, the number of forward citations, patent strength and competitive position based on a comparative study between China and the U.S. The results showed that the U.S. has an obvious advantage over the technological innovation capabilities compared to China in the field of CCS technology. The global total number of granted patents in the field of CCS technology was 2325 by the end of 2015, there were 703 and 468 granted patents in U.S. and China respectively. CCS technology in the U.S. has arrived at the stage of growth, or even maturity but is still at the research and development stage in China. Although the number of patents for Chinese CCS technologies is very close to that of the U.S. and is ranked second, China should be focused on enhancing its technological capabilities and patent quality. The policy implications of these research findings and the research limitations are also noted.
\end{abstract}

Keywords: technological innovation capability; carbon capture and storage technology; patent quality; patent information analysis; $\mathrm{CO}_{2}$ emissions

\section{Introduction}

Since human society entered the industrial age, about $8 \%$ of fossil fuel resources have been consumed, which has produced an estimate of 400 gigatons of carbon (Gt-C). These emissions were released back into our atmosphere in the form of $\mathrm{CO}_{2}$ [1]. According to statistics, despite increasing awareness of climate change, the average annual increase in emissions was $2.9 \%$ per year during the period from 2000 to 2005, compared to $1.1 \%$ per year during the period from 1990 to 2000 [2]. The Intergovernmental Panel on Climate Change (IPCC) concluded that the global average surface temperatures have increased by $0.74 \pm 0.18{ }^{\circ} \mathrm{C}$ during the twentieth century [1] and increasing anthropogenic greenhouse gases (GHG) concentrations are the principal contributor to most of the rise in global average temperatures. Therefore, $\mathrm{CO}_{2}$ has become one of the most significant anthropogenic greenhouse gases [3]. 
Carbon Capture and Storage (CCS) is a complex technology and consists of sets of technological components associated with capturing, transporting and storing $\mathrm{CO}_{2}$ deep underground; it is the only technology that reduces carbon emissions from coal-fired power plants [4]. As shown in Figure 1, the contributions of CCS technology to reduce $\mathrm{CO}_{2}$ would reach about $12 \%$ of the cumulative emissions reductions by 2050 and according to the estimation of International Energy Agency (IEA), $94 \mathrm{Gt} \mathrm{CO}_{2}$ will be captured and stored between 2013 and 2050 under the 2DS $\left(2{ }^{\circ} \mathrm{C}\right.$ scenario) [5], around $56 \%$ or $52 \mathrm{Gt}$ of total carbon dioxide captured is from power sector, $31 \%$ or $29 \mathrm{Gt}$ is captured from industrial processes and $14 \%$ or $13 \mathrm{Gt}$ is captured from fuel transformation [6]. Therefore, CCS technology is critical in order to meet the goals of the Paris Agreement on the climate [7], and, because the future of CCS technology is promising and predictable, there is a growing international interest in promoting CCS technology, more and more intergovernmental organizations focused on the demonstration and development of CCS technology, such as the United Nations Framework Convention On Climate Change (UNFCCC), the Carbon Sequestration Leadership Forum (CSLF), the G8, the International Energy Agency (IEA) and the Asia Pacific Partnership for Clean Development and Climate (APP) and so on [4].

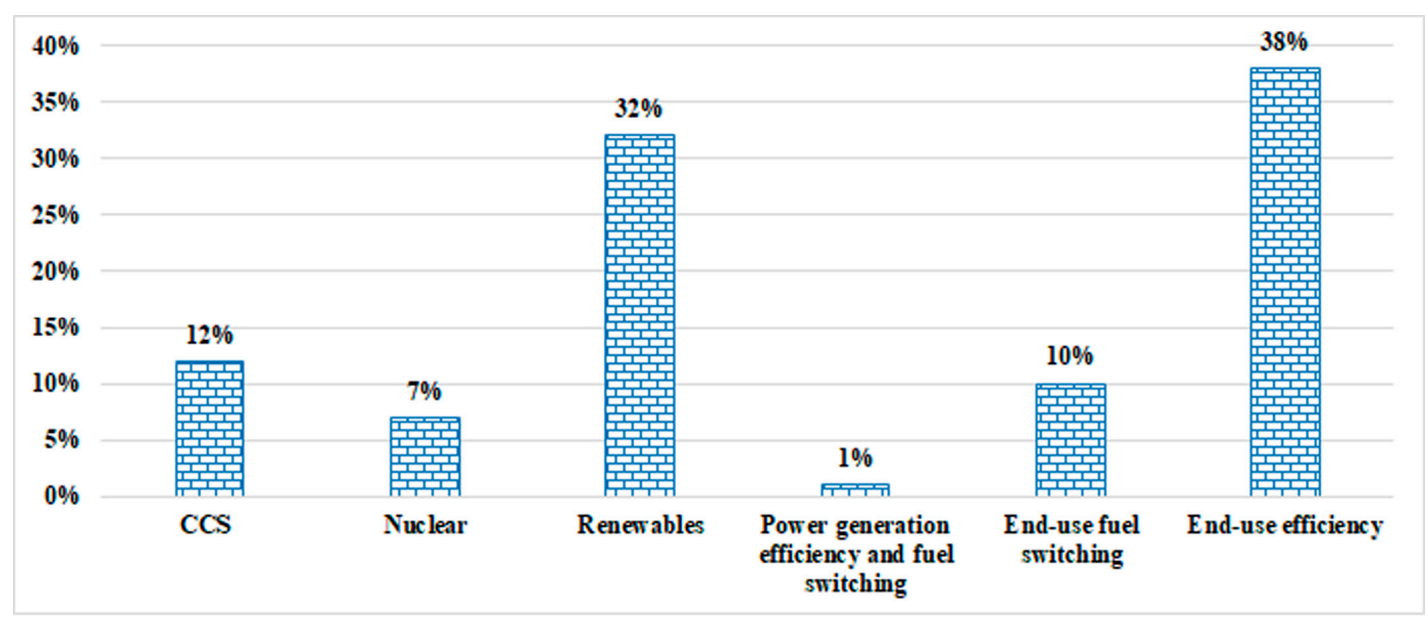

Figure 1. Carbon Capture and Storage (CCS) is a key contributor to global emissions reductions. (Source: IEA, Energy Technology Perspectives, 2016) [5].

Although technological innovation is regarded as an engine of promoting economic growth, how to assess technological innovation in a scientific way is not easy; many attempts, such as asking experts, research and development (R\&D) expenditure and total factor productivity (TFP), have been made by researchers and practitioners to do this [8]. The patent system is one of the most important available institutions that provides legislative protections for innovation. Normally, the assignee would possess the exclusive rights, such as making, using, offering to sell and selling or importing for a certain period of time, if their patent is granted by a patent office. Meanwhile, the assignee is obligated to disclose their innovative information in a manner that is sufficiently clear and complete, so as to allow a person skilled in the relevant field of technology to duplicate the invention [9]. The requirement of technical disclosure forces patent information to shed light on innovative activities. As a result, patents are regarded as one of important outputs of knowledge production [10]. Therefore, patent information is focused on by economists, industrialists and policy makers for the following reasons: It could provide an effective incentive for innovative activities, it could reflect the dynamic of technological change and it could also provide an important way for inventors to obtain economic returns from technological innovations [11]. Therefore, the analysis of patent information has long been regarded as an important way of investigating various aspects of technological changes and understanding trends in the innovative activities of a particular technology [12]. JinHyo Joseph Yun et al. applied patent citation and reference to investigate the effect of distance on open innovation [13]. Sangsung Park and 
Sunghae Jun proposed a technology analysis methodology based on Bayesian networks and a linear count model to analyze patent documents [14]. Byeongki Jeong and Janghyeok Yoon applied patent information analysis to study the industrial competitive intelligence in light of technology subject and firm level [15].

More and more countries/regions have begun to realize the increasing importance of CCS technology to control the $\mathrm{CO}_{2}$ effectively. In 2011, China has overtaken the U.S. and become the largest electricity producer with $21 \%$ of the total power generation in the world [16]. As the biggest emitter of $\mathrm{CO}_{2}$ in the world, China is regarded as a key player in the reduction effort of global $\mathrm{CO}_{2}$ [17]. According to the ACT (Accelerated Technology) Map scenario, the United States will account for the largest share of CCS deployment in 2020 and China is anticipated to have significant technological capacity and will account for the largest global share of CCS deployment by 2050 [2]. CCS for power generation is dominant in China, OECD Americas, OECD Europe and other non-OECD countries over the period to 2050 and China alone will account for $28 \%$ of the $\mathrm{CO}_{2}$ captured globally through 2050, followed by OECD Americas [6]. The patent activities occurring in the U.S., Japan, China and South Korea are responsible for $64 \%$ of the innovations in the field of $\mathrm{CO}_{2}$ capture technology [18]. A large number of patents have been filed for $\mathrm{CO}_{2}$ removal and separation and there has also been a sharp increase in the number of patents regarding sorbents, solvents and membranes over the period from 2006 to 2010. The number of patents on $\mathrm{CO}_{2}$ capture will continue to increase in the coming decade [19].

The main purpose of this paper is to assess the capabilities of the technological innovation of CCS in China as compared to that in the U.S. through the analysis of patent information. This paper is organized as follows: Section 2 explains the research methodology and patent search, Section 3 presents the analysis of patent information, Section 4 describes the discussion and conclusions and Section 5 states the policy implications and the limitations of our research.

\section{Methodology and Patent Search}

\subsection{Research Methodology}

It is known that the top $10 \%$ of the most valuable patents account for $93 \%$ of the total sample value of all patents [20]. This means that the majority of patents have little value and only a small number of patents are valuable. Therefore, when we carry out an analysis of patent information, the results may be misleading if we only pay attention to counting the number of patents but do not account for the value of patents. There is a paradox regarding the utilization of patent information. On the one hand, it is true that many patent indicators have been widely used to assess technological innovation; on the other hand, more and more studies also show that innovation capability could be effectively measured by selecting patent indicators [21]. In other words, taking into consideration the noise and biases in patent information, it is necessary to select proper indicators according to the purpose of research [22].

The technological capabilities and strategies of an assignee could be effectively determined by analyzing the quality of its patents. Many indicators have been used to assess the value or quality of a patent; for example, the number of patents, the percentage of patent growth, technology strength, number of patent citations, patent family size and so on [23]. Due to accessibility and persuasiveness, for the purpose of this study, the following indicators will be employed to measure the technological innovation of CCS: These are the lifespan of a patent, number of claims, number of forward citations, patent strength and competitive position.

\subsection{Retrieval of Patent Information}

To perform the patent search, we used the software package INNOGRAPHY ${ }^{\circledR}$, available from https://www.innography.com/. INNOGRAPHY founded in 2007, and based in Austin, Texas of the U.S., it provides patent search and intellectual property analytics software to help leading patent holders, innovators and decision-makers all over the world achieve more business value 
and market opportunities from intellectual property investments. The proprietary software suite of INNOGRAPHY ${ }^{\circledR}$ correlates 100 million patent documents with many other data sources, such as financial, litigation, market and business databases, as well as providing unique visualization technologies, which enable users to quickly obtain valuable insights for optimizing their patent portfolios, tracking current and potential competitors, identifying the litigation risks and following innovation trends. INNOGRAPHY continually monitors and improves its algorithms reflecting the shifts in trends over time. With more than 350 global users across all product industry categories, INNOGRAPHY achieves user satisfaction far above the industry average and has been used widely both in academia and business.

To perform an analysis of patent information, the first and foremost task is to compose a scientific patent search string. In order to improve the relevancy of our patent retrieval, we looked through not only relevant scientific literatures, including books and articles published in multiple disciplines, to achieve a more complete and correct understanding of CCS technology and collect the core keywords but also relevant patent documents directly related to CCS technology, which contains the core keywords in their title, to collect the synonyms or other expression forms of the core keywords for the patent search string. To be specific, firstly, we used "carbon," " $\mathrm{CO}_{2}$ " and "carbon dioxide" as the queries to define the term of "Carbon"; secondly, in order to collect the patent documents for the purpose of defining "capture and storage" of CCS technology, we used captur*, storag* and stransport* as prefixes as the queries and besides, we also used "sorbent," "delivery," "adsorption," "separation," "adsorbent" and "sequestration" as the supplementary queries; a patent document is regarded as valid if any term of both "carbon" and "capture or storage" are appeared simultaneously in the field of "title or abstract or claims" of a patent document.

Then, to ensure the pertinence factor, we extracted the patent classifications from the patent documents directly related to CCS technology. Finally, our patent search string for CCS technology was composed by combining the keywords with patent classifications, using the "AND" operator. It is to be noted that, regarding the patent search string, our study also referred to a previous publication of the World Intellectual Property Organization (WIPO) [24]. Of course, we modified this somewhat, according to the features of INNOGRAPHY, the patent search system employed in our study. Finally, we singled out CCS patents by searching for the keywords in the title, abstract and claims.

\section{Analysis}

\subsection{Summary Statistics}

\subsubsection{Annual Trend of Patent Activities of CCS Technology}

The analysis of annual distributions or changes of patent applications could help us understand the development trends of a specific technological sector [25]. Figure 2 presents the time series of patent application for CCS technology in China, the United States and the world. It can be seen that the numbers of patents for CCS technology in the United States had been increasing since 2002 and reached a peak in 2013, while in China, they have been increasing since 2007 and experienced a sharp increase since 2015. In 2005, a special report on the CCS technology was published by IPCC, this report not only is an extremely valuable and detailed reference document [26] but also is regarded as the most important milestones for CCS technology [27]. Furthermore, both the CoP 11 in Montreal and the first National Conference on CCS technology in The Netherlands were also held in 2005, the projects and plants for CCS implementation became more concrete during the period of time between 2005 and 2006 [28]. These facts/events may contribute to the rapid growth of patent applications of CCS technology after 2006.

In the U.S., CCS technology has been developed as a key technology in the fossil fuel R\&D programs of the U.S. for over a decade, there were 150 projects related to CCS technology carried out in the U.S. between 2000 and 2008, the total investments doubled from USD 20 million per year in the 
beginning of the millennium to USD 40 million in 2005, after that, investments in CCS rose to nearly USD 140 million in 2008 [29]. Therefore, as one of the countries, who has demonstrated the strongest interest and highest level of investment in CCS technology [30], the U.S. also takes a leadership role in the patent activities of CCS technology. In China, as the largest emitter of $\mathrm{CO}_{2}$ in the world, it is necessary to deploy the CCS technology, actually, China is promoting the demonstration projects of CCS technology in recent years [31]. As a result, in the field of CCS technology, the technological innovation and its patent protection are strengthened in both countries. It also can be seen from the figure that, although the annual trend of patent counts for CCS technology between the United States and China are similar, the patent activities of CCS technology in China is slower than that in the U.S.

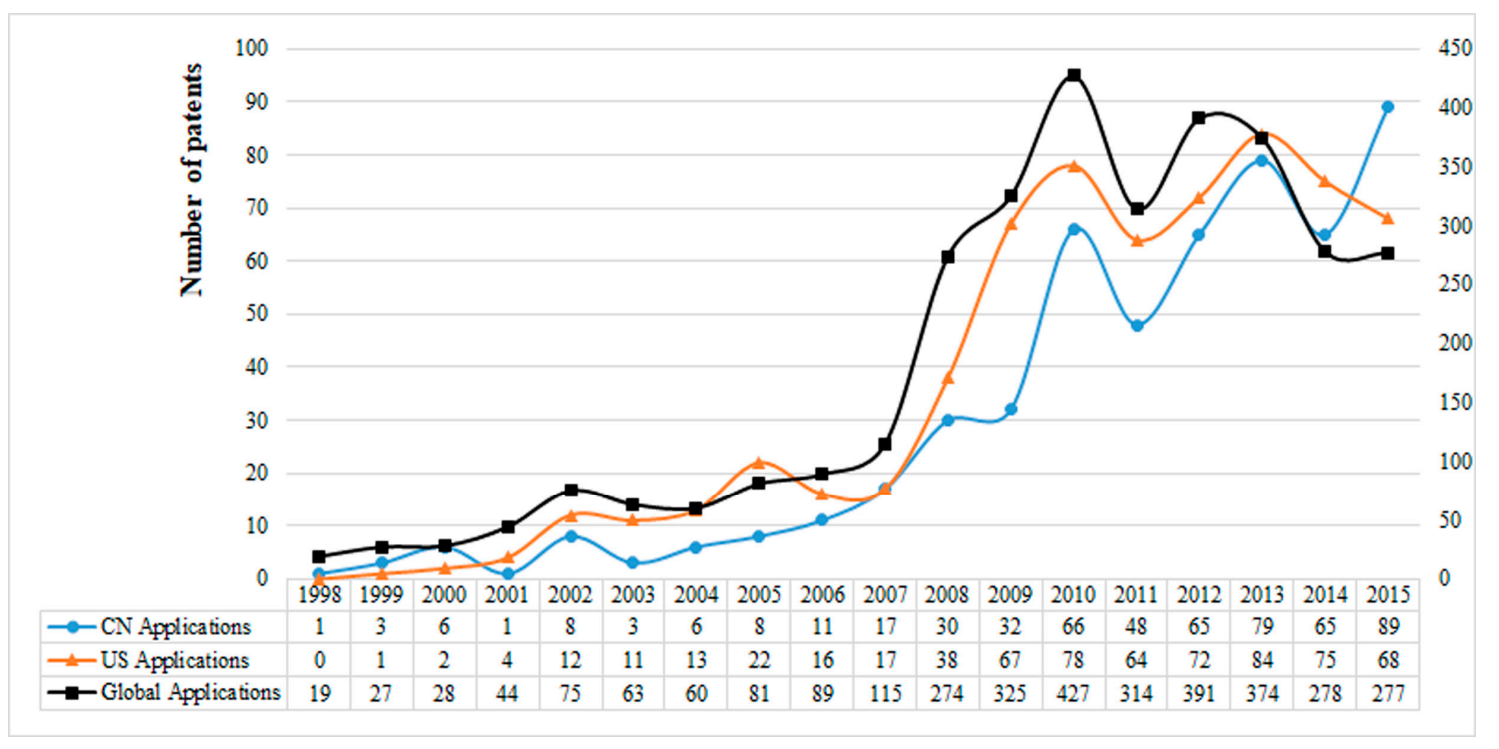

Figure 2. Annual trend of patent applications of CCS technology.

In addition, the development of CCS technology will depend on both internal and external conditions, the former includes the performance effectiveness and economics and the latter includes the emission-reduction target, unit price of emission allowance and economics of technology [32]. Therefore, the fluctuation of patent number after 2010 may to some extent reflect the attitude and its changes toward the acceptance and investment of CCS technology.

It is to be noted here that a patent document is published 18 months from the date of its filing. In other words, a patent document is held as a confidential document and cannot be searched by the public within 18 months of filing, the patent numbers of CCS technology in both 2016 and 2017 are incomplete. Therefore, the patent information in these years would not be treated in this study.

\subsubsection{The Top 10 Patent Assignees of CCS Technology}

Analyzing the patent applicants would disclose the main participants and competitors of technological innovation in a specific technical sector and provide the information about competitive situations and research directions [33]. Table 1 shows the top 10 assignees in global CCS patent activities. As is shown, the General Electric Company filed 383 CCS patents and became the applicant with the largest number of patent applications. It is followed by Air Liquide (106 patents) and the Exxon Mobil Corporation (104 patents). Most of the top 10 applicants are from North America and Europe, the United States has three applicants and France has two applicants. Both Mitsubishi Heavy Industries, Ltd. and Air Liquide filed patents earlier than other companies in the field of CCS technology. Both the Exxon Mobil Corporation and Mitsubishi Heavy Industries, Ltd., are more active in patenting activities in CCS technology in recent years among the top 10 applicants. Therefore, it may be concluded that the applicants listed in Table 1 invested more R\&D resources and obtained more 
innovative achievements in the field of CCS technology and they would also have more competitive advantages over technological innovation or patent activities.

Table 1. Top 10 patent applicants of CCS technology.

\begin{tabular}{ccccc}
\hline Applicant & Patents & Nation & $\begin{array}{c}\text { First Filing Date } \\
\text { (DD/MM/YYYY) }\end{array}$ & $\begin{array}{c}\text { Proportion of the Recent } \\
\text { Three Years (2015-2017) }\end{array}$ \\
\hline General Electric Company & 383 & U.S. & $06 / 09 / 2001$ & $2.61 \%$ \\
Air Liquide & 106 & FR & $01 / 06 / 1987$ & $2.83 \%$ \\
Exxon Mobil Corporation & 104 & U.S. & $06 / 05 / 2008$ & $26.92 \%$ \\
CO S Solution Inc. $_{\text {DF }}$ & 71 & CA & $11 / 07 / 2002$ & $18.31 \%$ \\
IFPergies Nouvelles & 68 & FR & $09 / 11 / 2007$ & $16.18 \%$ \\
Royal Dutch Shell plc & 65 & NED \& UK & $04 / 03 / 2002$ & $1.54 \%$ \\
Mitsubishi Heavy Industries, Ltd. & 60 & JP & $22 / 06 / 1984$ & $18.33 \%$ \\
Saudi Arabian Oil Company & 53 & KSA & $28 / 02 / 2006$ & $15.09 \%$ \\
Commonwealth Scientific \& & 52 & AU & $22 / 03 / 2002$ & $1.92 \%$ \\
Industrial Research Organisation & 50 & U.S. & $12 / 10 / 2004$ & $6.00 \%$ \\
Corning Incorporated & & &
\end{tabular}

\subsubsection{The Top 10 Countries of CCS Patent Applications}

The geographical distribution of patents reflects the different intensity of R\&D and market competition in different countries and region [34]. Figure 3 illustrates the top 10 countries and region of patent applications in the field of global CCS technology. It is found that the United States has the largest number of CCS patent applications (708). Apart from the U.S., extensive patent applications are seen in countries or region like China (663), European Patent Office (EPO, 441), Canada (332) and Japan (301). Among the top 10 countries for CCS patent applications, there are four countries from Asia, three countries or regions from Europe and two countries from North America.

Currently, CCS technology is considered to have technical feasibility in large-scale commercialization. Many R\&D activities were carried out to develop technologies in many countries, which contribute to the implementation of CCS [26]. Therefore, it may be concluded that CCS technology would be used more widely and achieves a faster growth in the countries or region listed in Figure 3. In addition, it can be found that, by crossing the information about the nations of the applicants (in Table 1) and the geographical distribution of patents, the U.S. not only had the largest number of patents but also accounted for the most of top 10 applicants; with the exception of China, each of the top 5 countries had at least one of top 10 applicants listed in Table 1; although Chinese total number of patents ranked the second globally, next only to the U.S., none of applicants in China became the top 10 applicants.

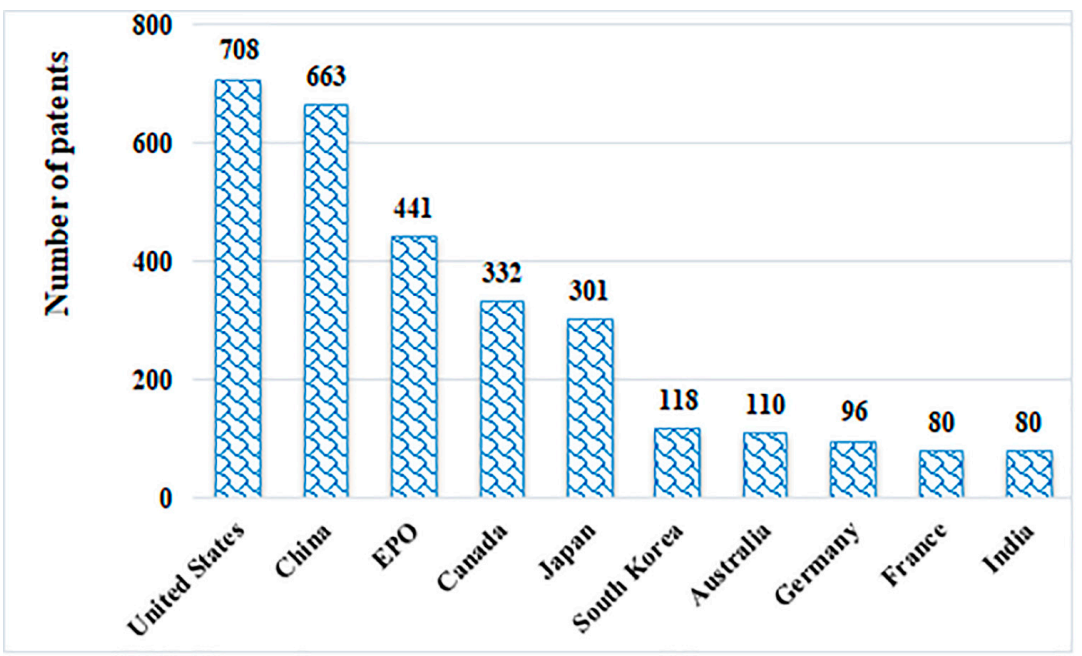

Figure 3. Top 10 countries/region of CCS patents. 


\subsubsection{Patent Activities of Technological Components of CCS}

CCS technology is not a single technology but rather a set of technological components [35]. The infrastructure of CCS technology can be divide into three components: capture, transportation and storage [36]. Table 2 shows the patent activities of three components of CCS technology. It can be seen that, in terms of patent activities of carbon capture technology, the global total number of patent applications is 2366. Either application number or granted number, China is far behind the U.S. As to the proportion of patent applications in the last three years, China (21.62\%) is similar to the U.S. $(20 \%)$. General Electric Company is the applicant who has the largest number of patents in the field of CCS technology in both China (36) and the U.S. (58).

Table 2. Patent activities of technological components.

\begin{tabular}{|c|c|c|c|c|}
\hline \multicolumn{5}{|c|}{ Carbon Capture } \\
\hline & $\begin{array}{c}\text { Number of } \\
\text { Applications }\end{array}$ & Granted Patents & $\begin{array}{l}\text { Proportion of the Recent } \\
\text { Three Years (2015-2017) }\end{array}$ & $\begin{array}{l}\text { Applicant with the Largest } \\
\text { Number of Patents }\end{array}$ \\
\hline $\mathrm{CN}$ & 333 & 160 & $21.62 \%$ & General Electric Company \\
\hline US & 515 & 369 & $20 \%$ & General Electric Company \\
\hline Global & 2366 & 998 & $22.62 \%$ & General Electric Company \\
\hline \multicolumn{5}{|c|}{ Carbon Transportation } \\
\hline & $\begin{array}{c}\text { Number of } \\
\text { Applications }\end{array}$ & Granted Patents & $\begin{array}{l}\text { Proportion of the Recent } \\
\text { Three Years (2015-2017) }\end{array}$ & $\begin{array}{l}\text { Applicant with the Largest } \\
\text { Number of Patents }\end{array}$ \\
\hline $\mathrm{CN}$ & 407 & 206 & $16.71 \%$ & $\begin{array}{l}\text { China Petroleum \& } \\
\text { Chemical Corporation }\end{array}$ \\
\hline US & 402 & 308 & $17.91 \%$ & General Electric Company \\
\hline Global & 2111 & 1140 & $11.84 \%$ & General Electric Company \\
\hline \multicolumn{5}{|c|}{ Carbon Storage } \\
\hline & $\begin{array}{l}\text { Number of } \\
\text { Applications }\end{array}$ & Granted Patents & $\begin{array}{l}\text { Proportion of the Recent } \\
\text { Three Years (2015-2017) }\end{array}$ & $\begin{array}{l}\text { Applicant with the Largest } \\
\text { Number of Patents }\end{array}$ \\
\hline $\mathrm{CN}$ & 459 & 293 & $41.39 \%$ & Tsinghua University \\
\hline US & 397 & 297 & $22.42 \%$ & General Electric Company \\
\hline Global & 2153 & 1085 & $19.37 \%$ & General Electric Company \\
\hline
\end{tabular}

In terms of patent activities of carbon transportation technology, globally, there are 2111 patents. Although China (407) has slightly more patent applications than the U.S. (402), the number of granted patents in China (206) is a lot less than the U.S. (308). Regarding the proportion of patent applications, China (16.71\%) and the U.S. (17.91) without much different. Although China Petroleum \& Chemical Corporation is the applicant who has the largest number of patents (15) in Chinese carbon transportation technology and General Electric Company is the applicant who has the largest number of patents not only in the U.S. (24) but also in the world (135).

When it comes to patent activities of carbon storage technology, there are 2153 patents globally, there are more patents filed in China than the U.S., the total number of granted patents is roughly the same in the two countries, however, China has a higher proportion of patents $(41.39 \%)$ in the past three years than the U.S. (22.42\%). As for the patent applicant, similarly, although Tsinghua University is the applicant who has the largest number of patents (10) in Chinese carbon storage technology, General Electric Company is the applicant who has the largest number of patents not only in the U.S. (19) but also in the world (95).

\subsection{Lifespan of Patents}

The Lifespan of Patent (LP) is a period in which the patentee pays an annual fee to maintain the validity of a patent [37]. Therefore, the calculating formula of LP would be illustrated as: LP for valid or invalid patent $=$ current date or patent expiration date - patent application date. According to the relevant provisions of Patent Law and the Rules for Implementation of the Patent Law of China, 
the duration of patent right shall be twenty years and ten years for invention patents and utility models/designs and the patentee shall pay an annual fee beginning with the year in which the patent right was granted. In the U.S., there are three basic types of patents: Utility patents, design patents and plant patents, the duration of both utility patents and plant patents is 20 years and the duration of a design patent is 14 years. Once a utility patent is granted, the inventor shall pay the fees of the period maintenance at 3.5, 7.5 and 11.5 years to the United States Patent and Trademark Office (USPTO) in order to keep their patent in effect. Therefore, LP could be thought of as the duration of a patentee maintaining the patent and the duration of patent viability is directly related to the fees for maintenance.

As is shown in Table 3, in China and the U.S., the schedule of fees for different types of patents present a periodical increasing trend, the longer the duration, the higher the maintaining fees. In other words, for longer patent durations, a patentee will have to afford higher costs. Actually, not only China and the U.S. but many other countries or regions have similar provisions. From this point of view, LP would be an important indicator of patent evaluation [10]. Only if technologies protected by a patent are they competitive and have value in the market and the patentee would be willing to pay the cost of keeping the patent valid. On the contrary, the patentee would not pay the cost and would waive patent protection once a technology is proved to be valueless.

Table 3. The fees for the patent maintenance in China and the U.S.

\begin{tabular}{cccc}
\hline \multicolumn{4}{c}{ Annual Fees for Three Types of Patents in China (Currency: RMB) } \\
\hline \multicolumn{2}{c}{ Invention } & Utility Model \& Design \\
\hline Year & Annual Fees & Year & Annual Fees \\
\hline $1-3$ & 900 & $1-3$ & 600 \\
$4-6$ & 1200 & $4-5$ & 900 \\
$7-9$ & 2000 & $6-8$ & 1200 \\
$10-12$ & 4000 & $9-10$ & 2000 \\
$13-15$ & 6000 & & \\
$16-20$ & 8000 & & \\
\hline Patent Maintenance Fee Schedule in the U.S. (Currency: USD) \\
\hline Year & Fee & Small Entity Fee & Micro Entity Fee \\
\hline $1-3.5$ & $/$ & $/$ & 400 \\
$3.5-7.5$ & 1600 & 800 & 900 \\
$7.5-11.5$ & 3600 & 1800 & 1850 \\
$11.5-20$ & 7400 & 3700 &
\end{tabular}

According to the calculation formula presented above, the LP distribution of CCS patents can be calculated and shown as Figure 4. The LP of a large number of global CCS patents are concentrated in three to nine years, especially at five years, there are 188 patents. The U.S. has the same distribution as the global CCS patents. However, the LP for most of Chinese CCS patents are concentrated in years two to seven and the LP at three years accounts for the majority of patents. The average LP of global CCS patents is 7.4 years; it is 6.8 years in the U.S. and 5.3 years in China. There are 949 patents that survived more than five years in the global CCS patents, accounting for $62.3 \%$ of the total patents, the percentage of patents with more than 10 years LP reached $18.1 \%$. There are even 58 patents in this technological sector that have been maintained for 20 years, which is the longest duration for a patent right. 


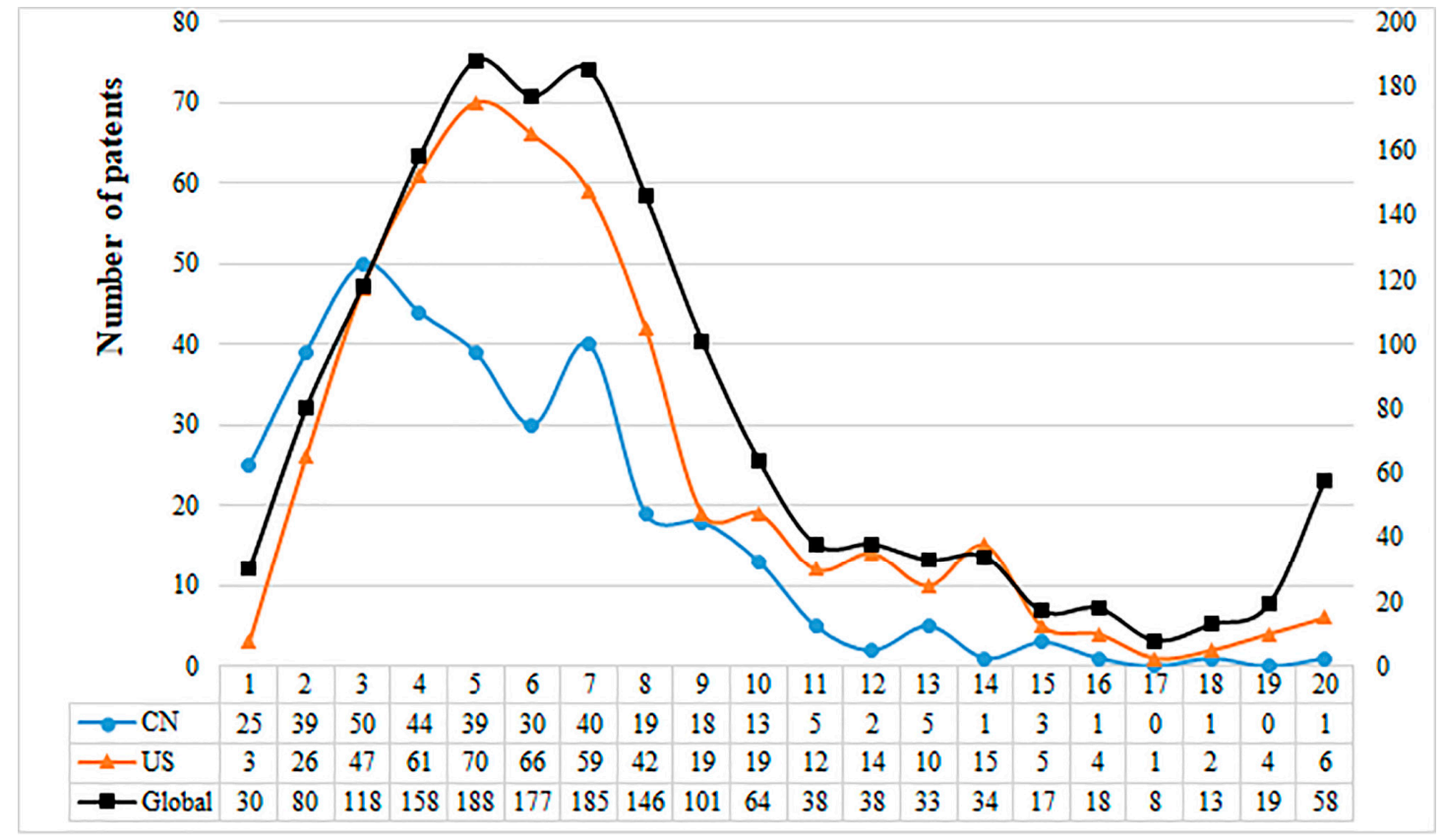

Figure 4. The lifespan distribution of CCS patents.

As mentioned above, taking the cost into consideration, for a patented technology, a longer duration means a greater market competiveness and technological value and it is more likely to be an important patent in a particular technological sector. Statistics shows that there are 116 patents maintained more than 15 years in the global CCS technological sector. Among them, there are 17 patents applied for in the U.S.; by contrast, just three patents were applied for in China. Up to now, CN1039700 filed by Lianyungang Chemical Plant in 1995 and transferred to Debang Chemical Industry Group Co., Jiangsu in 1996, is the only patent has been maintained for 20 years in Chinese CCS technology. In this patent, a method for producing synthetic ammonia is revealed, wherein carbon monoxide transformation and a reduction in $\mathrm{CO}_{2}$ are also included.

From the point of view of patent holders, both Texaco Co. and Mitsubishi Group have three important patents with a 20-year LP. The Texaco Co. is one of the biggest oil companies in the United States and its three patents were granted in the United States, Europe and Canada separately. The Mitsubishi Group also holds three patents with LPs of 20 years, which were filed in 1966, 1981 and 1991 respectively, these patents have expired now. Petra Nova Project, the world's largest Carbon Capture project, was officially put into operation in January 2017. Mitsubishi Heavy Industries played an important role in providing technical support for the project. Additionally, both British Gas and French Elf Aquitaine hold two patents with LPs of 20 years and the two patents of British Gas are members of patent family mutually and are granted in Europe and Canada, respectively.

\subsection{Number of Patent Claims}

Patent claims describe the subject matter of the invention, each patent has one or more patent claims. According to the Article 26 and Article 59 of the Patent Law of China, Claims are necessary documents for filing an invention or utility model, they should state the extent of the patent protection asked for and their terms also determine the extent of protection of the patent right. It could be considered that the patent claim illustrates the scope of protection of a granted patent. A typical patent document would contain a number of claims and each claim represents an inventive contribution concretely and distinctly. Patent counts might distort the research conclusion, while patent claims would be a better indicator to assess technological innovation than direct patent counts and would correlate better with other indicators related to technology than patent counts [38]. 
As patent claims increased by $10 \%$, patent litigation increased by $1.4 \%$ [39]. During the legal proceedings of patent litigation, the litigation strategy used most frequently by a defendant is to make a request for the invalidation of the plaintiffs' patent claims. The specification of patent claims is decisive for the stability of a granted patent right when invalidation is requested. Furthermore, the interpretation of patent claims has a strong impact on the economic and legal value of a patent [40].

According to the Administrative Fee Schedules of SIPO [41], when the number of patent claims are more than ten, there is an additional charge of 150 RMB (Chinese Yuan) for each claim. Similarly, in order to reduce the number of claims and improve the quality of patent documents, the United States Patent Office (USPTO) introduced excess claims fees and the claims fees were increased sharply in December 2004 [40]. As a result, applicants have to bear more costs in order to file a patent. Taking into account the cost, a patent applicant might be unwilling to pay the additional charges for patent claims, unless they are convinced that the technologies protected by patent claims have enough marketable competitiveness and value.

Therefore, the number of claims can be used as an indicator of patent quality [42]. The more patent claims might mean more technological features and a more complicated technological solution, as well as being less likely to be completely invalidated. The numerical distributions of claims of CCS patents in China and the U.S. are shown in Table 4. The average number of patent claims in the U.S. is 19. However, it is just nine in China, which is far below the global average number. There are many patents which have 20 claims in the U.S., by contrast, there is a large number of patents with only four claims in China.

Table 4. Claims distribution of CCS granted patents.

\begin{tabular}{ccccccc}
\hline $\begin{array}{c}\text { Country } \\
\text { (Region) }\end{array}$ & Granted & Average & Median & $\begin{array}{c}\text { Mode } \\
\text { (Timers) }\end{array}$ & Minimum & Maximum \\
\hline CN & 337 & 9 & 6 & $4(36)$ & 1 & 79 \\
US & 487 & 19 & 17 & $20(55)$ & 1 & 130 \\
Global & 1499 & 16 & 14 & $20(100)$ & 1 & 320 \\
\hline
\end{tabular}

Note: the final number of samples is 1499 , there are 24 patent claims missing.

In the U.S., US6821501 filed by Shell Oil Company is a patent that has the largest number of claims (130). The patent disclosed not only a new process and apparatus for steam reforming of any vaporizable hydrocarbon to produce $\mathrm{H}_{2}$ and $\mathrm{CO}_{2}$ but also a design to capture good concentrations of $\mathrm{CO}_{2}$ for sequestration [43]. Accordingly, $\mathrm{CN} 100449841$ filed by Ztek Corp (from the U.S.) has the largest number of patent claims (79) in Chinese CCS patents. This invention provided a load station that can remove or significant reduce the emissions of greenhouse components $\mathrm{CO}_{2}$ and maintain environmental balance [44].

\subsection{Number of Forward Citations}

In a patent document, the citations include forward citations and backward citations. The former means a patent document is cited by other patent documents which are filed later, this may indicate that this patent is used as a prior art. The latter means the references of existing patent documents, they are the technologies and prior arts on which the patent document stands upon [45]. More references may indicate a broader technological base and even a stronger patent. Similarly, the more forward citations of a patent, the more valuable it may be and the patent would be more likely to be a basic patent in a specific technological sector.

A patent document is a record of technology innovation, the number of forward citations of a patent may reflect its importance and influence on industry [46]. Therefore, patent citations indicate the evolution of innovation activities and we can track the technological knowledge by the analysis of patent citations. Highly-cited patents would contain more technological information of particular importance [47]. Forward citations can be used to estimate the technological impact of a patented 
technology and it has been found that there is a strong correlation between the value of a patent and the number of its forward citations [48]. Patent counts themselves do not constitute a good measure of innovative output and forward citations are informative about patent value [49]. Compared to using only the unweighted patent numbers or data on R\&D expenditures, the information of patent citations would be a more effective tool for assessing the impact and importance of a particular technological innovation, because the prior patents cited in following patents are more likely to become relatively important precursors [50].

The number distribution of forward citations of CCS patents both in China and the U.S. as well as global are shown in Table 5. It can be seen that in the number of forward citations of CCS patents in the whole world, most of the patents concentrate in the interval of $0-50$, wherein nearly two-thirds of these patents have never been cited. There are only 29 CCS patents all over the world have been cited more than 50 times, less than $2 \%$ of the total number and among them, there are 28 patents filed in the United States; by contrast, there is only one patent with 53 forward citations filed in China.

Table 5. The distribution of forward citations of CCS patents.

\begin{tabular}{cccccc}
\hline $\begin{array}{c}\text { Number of } \\
\text { Forward Citations }\end{array}$ & $\mathbf{2} \mathbf{2 0 0}$ & $\mathbf{1 5 0 - 2 0 0}$ & $\mathbf{1 0 0 - 1 5 0}$ & $\mathbf{5 0 - 1 0 0}$ & $\mathbf{0 - 5 0 ( 0 )}$ \\
\hline CN & 0 & 0 & 0 & 1 & $356(170)$ \\
US & 1 & 2 & 7 & 18 & $473(238)$ \\
Global & 1 & 2 & 7 & 19 & $1612(1028)$ \\
\hline
\end{tabular}

In the U.S., US6389814 filed by Clean Energy Systems, Inc. is the patent that has the largest number of forward citations (295), in which, a combustion engine providing clean power for various applications and featuring low NOx production and low $\mathrm{CO}_{2}$ release into the atmosphere was disclosed [51]. In China, CN101905091 filed by Xinjiang University is the only patent among all the CCS patents whose number of forward citations is more than 50 that was not filed in the U.S. but in China. It was cited more than 7.5 times each year since 2010 and one kind of sub-critical fluid extraction apparatus and method of the biologically active ingredient were provided in the patent [52].

\subsection{Patent Strength}

Although PatentStrength ${ }^{\circledR}$ is a trade secret of INNOGRAPHY, it has been of interest over recent years, in both academia and business practice. INNOGRAPHY's PatentStrength ${ }^{\circledR}$, also called patent valuation algorithms, could be employed to estimate the strength score of a patent based on a variety of indicators including the number of patent claims, the types and number of patent citations, the number of different International Patent Classifications, the location of the patent assignee, other indicators, or any combination thereof. The information derived from a patent document and optionally other information related to a patent document can be used to calculate the strength score of each patent [45]. It presents an insight into a patent value and becomes an important tool for ranking the patents [53].

INNOGRAPHY developed a scale for patent strength from 1-100, with one corresponding to the lowest level of patent strength and 100 reflecting a true advance. Figure 5 shows the distribution of patent strength for CCS patents in both the U.S. and China. As is shown, the patent strength of 0-30 accounts for $45.6 \%$ of the global CCS patents and the distribution in China is the same. By contrast, the patent strength of most CCS patents in the U.S. are distributed in the scale of 30-100. Provided that the patent would be regarded as an important patent if its patent strength is more than 80 , then there are only 11 important patents in China, accounting for $8.6 \%$ of total Chinese CCS patents, while there are 111 important patents in United States, accounting for $23 \%$ of total U.S. patents. 


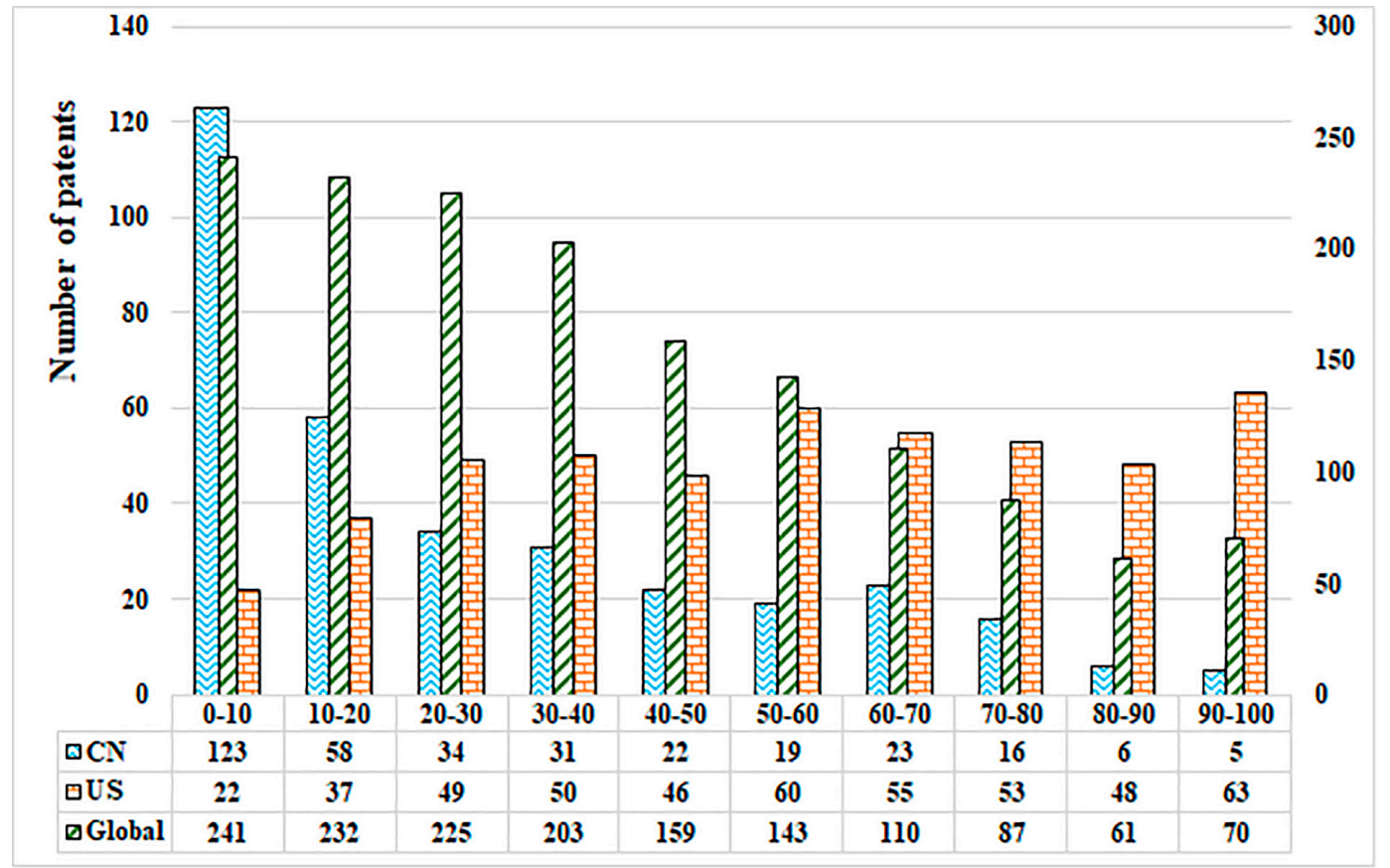

Figure 5. Distribution of patent strength of CCS patents.

In the U.S., US8846377 filed by $\mathrm{CO}_{2}$ Solutions Inc. (Québec, QC, Canada) is the patent that got the highest score on patent strength (94), this invention provided a process for capturing $\mathrm{CO}_{2}$ includes contacting a $\mathrm{CO}_{2}$-containing gas with an absorption mixture optionally within a packed reactor [54]. In China, CN1795257 filed by Alstom Technology Ltd. (from Baden, Switzerland) is the patent that has the highest score on patent strength, in which, a method for the production of gaseous products from a carbonaceous fuel gasifier was provided [55].

\subsection{Competitive Position of Top Assignees}

The market map is a powerful algorithm employed in INNOGRAPHY that provides a visual description of a competitive landscape. The map consists of a technological (horizontal) axis and a resources (vertical) axis. The former combines three key factors: Patents, classifications and citations and similarly, the latter also combines three key factors: Total revenue, patent litigation and number of locations. The assignee would have a greater ability to capitalize on its patents if it has a higher location on the resources axis and the assignee would also have a greater competitive strength on patent activities if it has a higher score on the technological axis. Therefore, the map indicates the competitive position of assignees in a particular technological field which implies the relative strength of technological innovation. We use INNOGRAPHY's market map framework to identify the leaders of technological innovation in the CCS domain. In this framework, as seen in Figures 6 and 7 generated automatically by INNOGRAPHY, the competitive position of various patent assignees of CCS technology in both the U.S. and China are compared, respectively, on the basis of their quality score of both technologies and resources.

Figure 6 presents the competitive position of the top 20 assignees in the field of CCS in the U.S. The geographical composition of the type of assignees show there are 11 domestic assignees and nine foreign assignees. Among all the domestic assignees, there are seven companies, three universities and one individual. Among all the foreign assignees, there are two from France and the other assignees are from seven different countries: Canada, The Netherlands, South Korea, Japan, Australia, Saudi Arabia and Italy. 


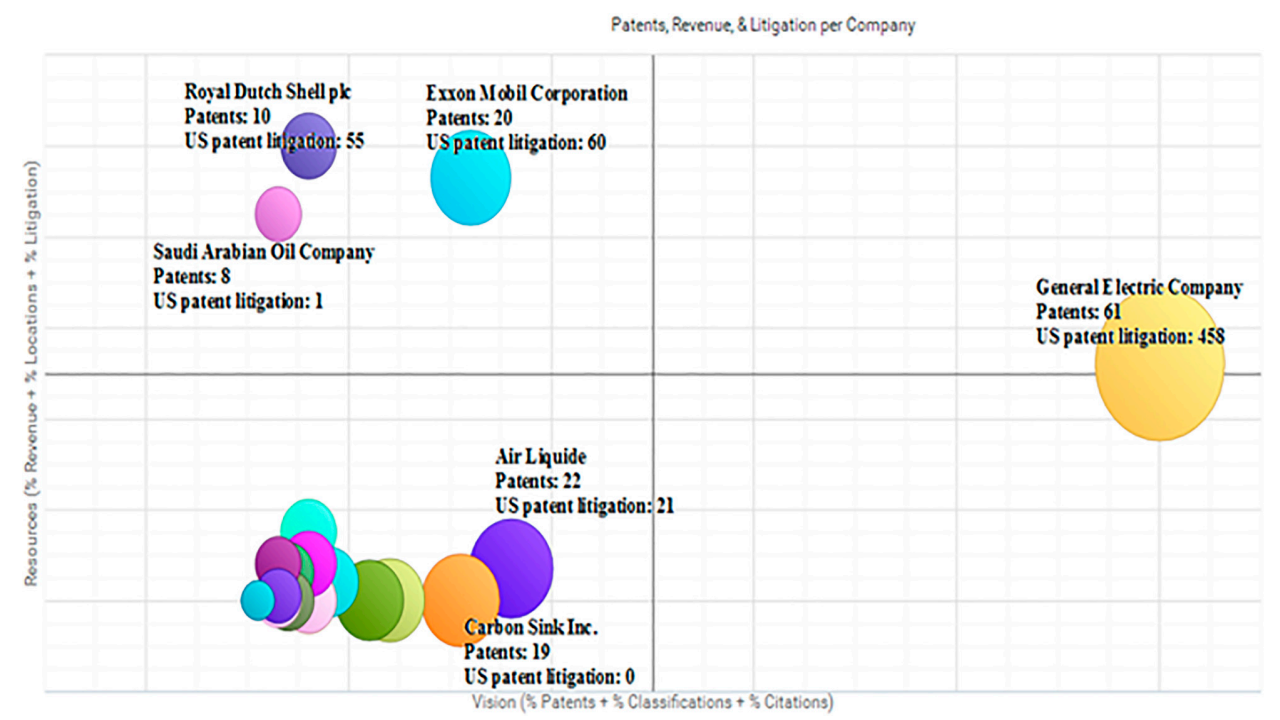

Figure 6. Competitive position of top patent assignees in the U.S.

It is shown that, in the CCS domain of the U.S., the General Electric Company (GE) is the only assignee located close to the area of the upper right quadrant. Therefore, GE, not only has a competitive advantage over patent activities but also has a competitive advantage over resources, so that GE would be the technological and marketable leader with stronger comprehensive capabilities. Royal Dutch Shell plc, the Exxon Mobil Corporation and the Saudi Arabian Oil Company are located in the upper left quadrant, they have obvious competitive capabilities in resources, so they are challengers in CCS market and would also be the potential buyers. The other assignees are located in the lower left quadrant, they are the main patent assignees in the field of CCS and they would be not only niche players or start-ups but also the followers and market entrants. There are no assignees located in the lower right quadrant.

Figure 7 depicts the competitive position of top 20 patent assignees in the field of CCS in China. As to the geographical composition of the type of patent assignees, just the same as in the U.S., there are also 11 domestic assignees and nine foreign assignees. However, among all the domestic assignees, there are eight universities and three companies and among all the foreign assignees, there are four from the U.S. and the others are from France, Canada, Australia, France and Saudi Arabia.

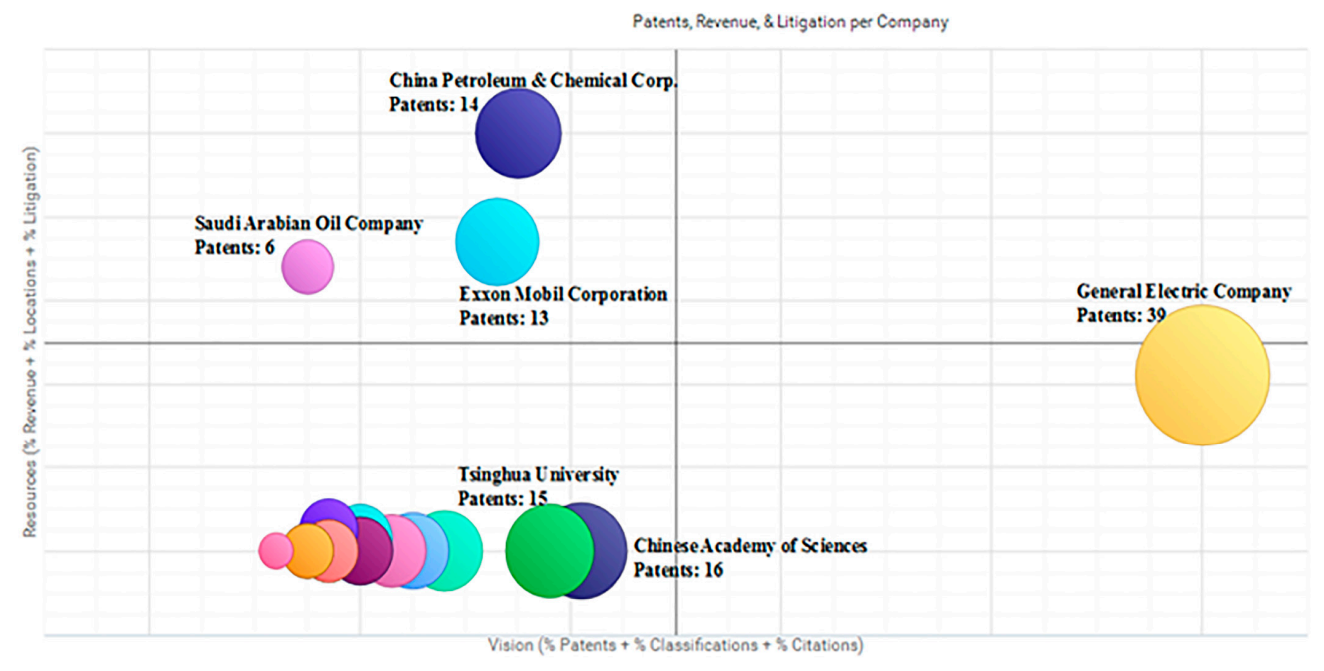

Figure 7. Competitive position of top patent assignees in China. 
In the market map of Chinese CCS technology, GE, the Exxon Mobil Corporation and the Saudi Arabian Oil Company are located at a similar coordinate position as they are in the U.S. and most of the top assignees are located in the lower left quadrant. Therefore, GE has greater comprehensive competitive capabilities in Chinese CCS Technology and China Petroleum and Chemical Corp., located in the upper left quadrant together with two foreign assignees, the Exxon Mobil Corporation and the Saudi Arabian Oil Company. There is also no assignee located in the lower right quadrant.

Based on a comparative analysis, it could be found that the proportion of foreign assignees is exactly the same between China and the U.S., there are nine foreign assignees in both of the two countries. In addition, we also can find that all of the foreign assignees of the top 20 patent assignees in China are the top assignees in the U.S. The different is that there are more universities in the top assignees in China than in the U.S. Furthermore, there are four companies from the U.S. among all top 20 assignees in China, however, there is no company from China among all top 20 assignees in the U.S.

\section{Discussion and Conclusions}

\subsection{Discussion}

It is well known that both China and the United States account for a great percentage of the emission of greenhouse gases and energy consumption in both countries depend heavily on coal energy [56]. As early as 2011, China had overtaken the United States and become the largest electricity producer in the world [16]. In the U.S., there is about $83 \%$ of the GHG emissions produced from combustion and nonfuel uses of fossil fuels, the consumption of fossil fuels will increase by $27 \%$ over the next 20 years, the $\mathrm{CO}_{2}$ emissions will increase from the current 6000 million tons per year to 8000 million tons per year by 2030, therefore, in order to reduce $\mathrm{CO}_{2}$ emissions, the U.S. Department of Energy (DOE) carried out the Carbon Sequestration Program to develop innovative and cost effective capture technologies [57]. In addition, to achieve the greenhouse gas emissions reduction target of Copenhagen Accord, China is expected to cut $3760 \mathrm{Mt} \mathrm{CO}_{2}$ emissions from the power sector by 2030, 20\% of the reduction will depend on CCS technology [58]. China has started to deploy CCS demonstration projects, the international efforts also provided valuable information on developing a CCS roadmap for China [59]. Study results show that CCS is an effective technological measure to reduce the emission of $\mathrm{CO}_{2}$, which is the most important long-lived anthropogenic greenhouse gas. Although there are different technologies to capture $\mathrm{CO}_{2}$ from gases and the large-scale implementation of CCS technology in power plants is linked to many challenges [60], CCS technology may grow to become a major industry in China and the U.S. According to the estimation of IEA, almost $80 \%$ of CCS technology is expected to be deployed in China and the United States [61].

In 2006, China's Medium- and Long-Term Program for Science and Technology Development (2006-2020) was released by State Council of P.R. of China, one of the main contents of the program is to develop the efficient, clean and near-zero emission fossil energy utilization technologies and then, CCS was highlighted as an important frontier technology in China; in 2007, the State Council of P.R. of China released National Climate Change Program (2007-2010), in which CCUS (Carbon Capture Utilization and Storage) technology was included as one of the key GHG mitigation technologies; and in the same year, China's Scientific and Technological Actions on Climate Change (2007-2020) was released, in which, CCUS technology was identified as one of the key tasks in the development of GHG control technologies in China [62]. Although the United States was one of the main investors in global CCS technology, it decreased its national investments to CCS technology since 2009 [63]. By contrast, there were 18 policies related to CCS technology released in China during the period of time between 2011 and 2014 [64], which makes CCS technology achieve a rapid growth in China. Taking Large Scale Integrated Projects (LSIP) for example, although the U.S. was the most active country, China had the largest number of LSIPs by September 2012 and more than half of all new early-stage LSIPs were located in China [16]. Therefore, it may be considered that the technological 
innovation and patent activities of Chinese CCS technology were promoted by these governmental policies. Therefore, the number of patent applications in Chinese CCS technology increased rapidly after 2007, even reached the peak and surpassed the U.S. in 2015.

A country or company can obtain its technological competitiveness through the sustainable technology, sustainable technology has been one of the most important problems in the field of technology analysis and patent information is one form of objective data for technology analysis [65]. Patent document contains substantial information regarding developed technology, so that patent information analysis is not only a popular research topic in management of technology but also a useful method of sustainable technological forecasting [66]. Patent-based indicators are increasingly used to assess the rate of innovation activities [67]. A quantitative analysis based on a structured dataset is not applicable for a patent's technological information [68]. Based on a patent analysis by some selected indicators, we found, generally, that, in the field of CCS technology, there is not a large gap in the total patent number between China and the U.S. but in patent capabilities and patent qualities, China is far behind the United States. It is obvious that, in the field of CCS technology, the United States has a higher level of capabilities in both technological innovation and patent activities compared to China. It means that although China ranked second in the total number of patent applications in the world, it only has an advantage with regard to patent quantity but not quality, its technological innovation level in CCS technology needs to be further improved in the near future.

\subsection{Conclusions}

Based on a summary analysis, we employed the lifespan of patent, number of claims, number of forward citation, patent strength and competitive position of top assignees to assess the technological capabilities of CCS from the perspective of a comparative study between China and the U.S.

The United States has seen the maximum patent applications and is closely followed by the large Asian market of China. The top countries of patent applications in the field of CCS are mainly from North America, Europe and Asia and both the United States and China have more CCS patents, this may mean that this two countries have achieved more innovations in the field of CCS technology than other countries. However, when it comes to the top 10 patent assignees, there is no assignee from China but there are three applicants from the United States. Furthermore, examining the patent filings by year reveals that the United States was faster than China in engaging in the innovation and patent activities of CCS, although the annual trend of CCS patent applications is similar between the two countries.

As is known that, capture, transportation and storage are the main components of CCS technology. The U.S. has obvious advantages over the patent activities of carbon capture technology. China has more patent applications in both carbon transportation technology and carbon storage technology. However, the U.S. has more granted patents in all the three main components of CCS technology. Taking into account the requirements of patent examination and grant, it can be concluded that the U.S. has stronger capabilities of technological innovation than China in the field of CCS technology. By contrast, the number of CCS patents in China increased rapidly in recent years and China also invested more and more innovative resources in CCS technology, especially in the carbon storage technology. The advantage of the U.S. in the field of CCS technology is also reflected by having enterprises with stronger innovative capabilities. General Electric Company is one of the most innovative competitors in the global CCS technology, it has filed lots of patents in all the three technological components of CCS and it is also one of the most important patent applicants in the U.S., China, even the world.

Compared with the United States, China has fewer patents that survived for 15 years or more. The average number of patent claims in the U.S. is 10 more than that in China. Among all the 29 patents, which have more than 50 forward citations, there is only one patent from China and all the others are from the U.S. When it comes to patent strength, more than $77 \%$ of global high-strength patents (patent strength is more than 80 ) are from the U.S.; by contrast, China only possessed about 
$8.4 \%$ of global high-strength patents. Therefore, as to the technological innovation management of Chinese CCS technology, one the one hand, it is necessary to improve the capabilities of technological innovation, on the other hand, it is also important to enhance the quality of patent document drafting and implement the patent strategies.

The America main assignees not only have a good competitive position in the U.S. but also in China. For example, GE is a leader in the development of both cleaner coal technologies and air quality control systems, it is at the forefront of the development of CCS. The major domestic assignees in China are universities. The majority of the motivation to apply for patent protection for a company is to improve the company's position in negotiations with partners, licensees and the financial sector [69]. By contrast, the motivation to get involved in patent activities for inventors of university-owned patents is mostly concerned with intangible rewards such as prestige, visibility, reputation and new stimuli for research, as well as the desire to get more funds for research but not for personal earnings [70]. The non-commercial motivation of filing patents makes Chinese universities just pay attention to the quantity of patents but not the maintenance of patents, therefore, although the share of granted patents of Chinese universities accounted for $67 \%$ of the total filing patents, the share of commercialization of granted patents just accounted for $9 \%$ of the total granted patents [71]. Therefore, that university-owned patents determine most of CCS patents in China indicate they would not be turned into practice and increase the possibility of their being waived. To a certain extent, it is also reflected by the differences in the developing stage of CCS technology between China and the U.S. In the United States, CCS technology has come into the stage of growth or even maturity, however, it is still at the stage of research and development in China.

This paper assessed the technological innovation capabilities of CCS technology from the perspective of patent information analysis, it contributes our understanding of how the innovation capabilities and patent activities of CCS technology differs between China and the U.S. This method also can be employed as a tool to identify the potential competitors and evaluate the quality of patent activities. The managers of technological innovation can know how to obtain the valuable patented technologies and carry out an effective technological management.

\section{Policy Implications and Limitations}

\subsection{Policy Implications}

This paper has presented a quantitative patent analysis in the field of CCS technology, the results of this empirical study have some obvious implication for public policies. Firstly, based on previous literature, some indicators have been developed to assess potential valuable or high quality patented technologies. This method would provide government agencies with valuable information that could help them to make efficient decisions about financial support to ongoing CCS projects. For the assignees in both the U.S. and China can well understand how to carry out patent activities and implement the patent strategies during the management of technological innovation.

Secondly, the number of patent claims is related to the drafting of a patent document. In order to improve the patent quality of CCS technology, the Chinese government should take some effective measures to encourage inventors to enhance the level of technological innovation and in the short-term focus on improving the quality of patent document drafting. Especially, as to the U.S., the assignees can bring their mature experience in using the patent system and initiative into full play, further enhance their patent quality of technological innovation.

Thirdly, a competitive position map of both the U.S. and China is illustrated. It is valuable for the assignees in both the U.S. and China to recognize correctly their advantages and capabilities in the technological innovation and patent protection of CCS technology, identify who will be their main competitors globally and get necessary information about the situation of technological innovation and patent protection of the main competitors. It is also useful for the Chinese government to 
formulate industrial developing policy plans for CCS technology, especially in promoting the activities of technological transfer and licensing as well as Mergers and Acquisitions.

Last but not least, in view of the rapid development and technological innovation of Chinese CCS technology, taking into account the improvement of patent quality, the Chinese government should guide the entities carrying out long-term patent strategy and patent layouts and apply patent protection overseas.

\subsection{Limitations of Our Research}

This study contributes our understanding of how the technological capabilities of CCS differs between the U.S. and China. However, there are still some limitations. First of all, it is well known that patent information just one aspect of innovation activities, the patent system would not protect all inventions and not all patentable inventions would be applied for patent protection by inventors. Furthermore, there are still other patent indicators which are valuable for assessing innovative capabilities but have not been used in this study.

The differences of patent system between the U.S. and China result in the differences of patent information in these two countries. For example, in the U.S., patent applicants have an obligation to disclose the prior arts to the patent office, otherwise, their patent applications would not be granted. However, it is not exactly the same case in China. These differences would have direct impact on the reliability of some of the patent indicators employed in this study.

In terms of research methodology, the criteria for selecting the indicators employed in our research is based on the consideration of patent quality and innovative assessment, which makes our analysis appear relatively simple and not detailed enough. Actually, as to the future research on patent analysis or the utilization of patent information, besides the analysis of patent bibliographic information, the other methods for patent mining, such as text mining, patent mapping, patent clustering and so on, would also be effective to achieve a specific research purpose.

In addition, the platform of patent search used in this study was developed by an America company, for this reason, some advantages of the U.S. in patent activities in CCS technology could be attributed to "home country bias." These limitations should be noted in future similar research.

Acknowledgments: The research work was supported by National Social Science Foundation of China under Grant No. 15BTQ047. The corresponding author is grateful for the financial sponsorship of Chinese Scholarship Council (CSC) to support his study in Max Planck Institute for Innovation and Competition as a visiting scholar and special thanks to my supervisor, professor Dietmar Harhoff, the director of Max Planck Institute for Innovation and Competition. He not only provides me with very nice research conditions but also offers me lots of valuable and constructive comments/suggestions for my research.

Author Contributions: Hong-Hua Qiu designed this study, wrote the paper and performed all the research steps. Jing Yang searched and preprocessed the patent information. All the authors cooperated and discussed and revised the paper.

Conflicts of Interest: The authors declare no conflict of interest.

\section{References}

1. Stephen, A. Rackley Carbon Capture and Storage, 2nd ed.; Elsevier, Butterworth-Heinemann: Oxford, UK, 2017; ISBN 9780128120415.

2. International Energy Agency. Energy Technology Perspectives 2008-Scenarios and Strategies to 2050; OECD/IEA: Paris, France, 2008; ISBN 978-92-64-04142-4.

3. NASA Goddard Institute for Space Studies (GISS). Variation of the Earth's Surface Temperature during the 20th Century. Available online: www.giss.nasa.gov (accessed on 3 November 2017).

4. Coninck, H.D.; Stephens, J.C.; Metz, B. Global learning on carbon capture and storage: A call for strong international cooperation on CCS demonstration. Energy Policy 2009, 37, 2161-2165. [CrossRef]

5. International Energy Agency. Energy Technology Perspectives; OECD/IEA: Paris, France, 2016; ISBN 978-92-64-25234-9. 
6. International Energy Agency. 20 Years of Carbon Capture and Storage: Accelerating Future Deployment; OECD/IEA: Paris, France, 2016; Available online: https:/ /www.iea.org/publications/freepublications / publication/20YearsofCarbonCaptureandStorage_WEB.pdf (accessed on 23 February 2018).

7. Rogelj, J.; Elzen, M.D.; Höhne, N.; Fransen, T.; Fekete, H.; Winkler, H.; Schaeffer, R.; Sha, F.; Riahi, K.; Meinshausen, M. Paris Agreement climate proposals need a boost to keep warming well below $2{ }^{\circ} \mathrm{C}$. Nature 2016, 534, 631-639. [CrossRef] [PubMed]

8. Nagaoka, S.; Motohashi, K.; Goto, A. Chapter 25-Patent Statistics as an Innovation Indicator. Handb. Econ. Innov. 2010, 2, 1083-1127.

9. Kürtössy, J. Innovation indicators derived from patent data. Soc. Manag. Sci. 2004, 12, 91-101.

10. Griliches, Z. Patent Statistics as Economic Indicators: A Survey. J. Econ. Lit. 1990, 28, 1661-1707.

11. Scherer, M. Patents and the Economy: The State of the Art. In Economic Patent Research with Respect to the European System; Harvard University: Cambridge, MA, USA, 1992.

12. Abraham, B.P.; Moitra, S.D. Innovation assessment through patent analysis. Technovation 2001, 21, $245-252$. [CrossRef]

13. Yun, J.H.J.; Jeong, E.S.; Lee, C.H.; Park, J.S.; Zhao, X. Effect of Distance on Open Innovation: Differences among Institutions According to Patent Citation and Reference. Sustainability 2017, 9, 1478. [CrossRef]

14. Park, S.; Jun, S. Technology Analysis of Global Smart Light Emitting Diode (LED) Development Using Patent Data. Sustainability 2017, 9, 1363. [CrossRef]

15. Jeong, B.; Yoon, J. Competitive intelligence analysis of augmented reality technology using patent information. Sustainability 2017, 9, 497. [CrossRef]

16. Huaman, R.N.E.; Tian, X.J. Energy related $\mathrm{CO}_{2}$, emissions and the progress on CCS projects: A review. Renew. Sustain. Energy Rev. 2014, 31, 368-385. [CrossRef]

17. Zheng, L.; Zhang, D.; Ma, L.; Logan, W.; Ni, W. The necessity of and policy suggestions for implementing a limited number of large scale, fully integrated CCS demonstrations in China. Energy Policy 2011, 39, 5347-5355. [CrossRef]

18. José, L.M.; Jacobo, P.; Raquel, P.-O.; David, P.; Sandra, R. Evolution of $\mathrm{CO}_{2}$ capture technology between 2007 and 2017 through the study of patent activity. Appl. Energy 2018, 211, 1282-1296.

19. Li, B.; Duan, Y.; Luebke, D.; Morreale, B. Advances in $\mathrm{CO}_{2}$, capture technology: A patent review. Appl. Energy 2013, 102, 1439-1447. [CrossRef]

20. Scherer, F.M.; Harhoff, D. Technology policy for a world of skew-distributed outcomes. Res. Policy 2000, 29, 559-566. [CrossRef]

21. Kang, C.W.; Su, H.N. Assessing innovation capability and scientific impact of industry through patented technologies. In Proceedings of the 2014 Portland International Conference on Portland International Conference on Management of Engineering \& Technology (PICMET), Kanazawa, Japan, 27-31 July 2014; pp. 1281-1290.

22. Basberg, B.L. Patents and the measurement of technological change: A survey of the literature. Res. Policy 2006, 16, 131-141. [CrossRef]

23. Hsieh, C.H. Patent value assessment and commercialization strategy. Technol. Forecast. Soc. 2013, 80, 307-319. [CrossRef]

24. World Intellectual Property Organization. Patent-Based Technology Analysis Report-Alternative Energy. Available online: http:/ / www.wipo.int/edocs/plrdocs/en/landscape_alternative_energy.pdf (accessed on 24 October 2017).

25. Tseng, F.-M.; Hsieh, C.-H.; Peng, Y.-N.; Chu, Y.-W. Using patent data to analyze trends and the technological strategies of the amorphous silicon thin-film solar cell industry. Technol. Forecast. Soc. 2011, 78, 332-345. [CrossRef]

26. Gibbins, J.; Chalmers, H. Carbon capture and storage. Energ. Policy 2008, 36, 4317-4322. [CrossRef]

27. Hansson, A.; Bryngelsson, M. Expert opinions on carbon dioxide capture and storage-A framing of uncertainties and possibilities. Energy Policy 2009, 37, 2273-2282. [CrossRef]

28. Alphen, K.V.; Voorst, Q.V.V.T.; Hekkert, M.P.; Smits, R.E.H.M. Societal acceptance of carbon capture and storage technologies. Energy Policy 2007, 35, 4368-4380. [CrossRef]

29. Alphen, K.V.; Noothout, P.M.; Hekkert, M.P.; Turkenburg, W.C. Evaluating the development of carbon capture and storage technologies in the United States. Renew. Sustain. Energy Rev. 2010, 14, 971-986. [CrossRef] 
30. Chaudhry, R.; Fischlein, M.; Larson, J.; Hall, D.M.; Peterson, T.R.; Wilson, E.J.; Stephens, J.C. Policy Stakeholders' Perceptions of Carbon Capture and Storage: A Comparison of Four U.S. States. J. Clean. Prod. 2013, 52, 21-32. [CrossRef]

31. Jaccard, M.; Tu, J.J. Show some enthusiasm but not too much: Carbon capture and storage development prospects in China. Glob. Environ. Chang. 2011, 21, 402-412. [CrossRef]

32. Koo, J.; Han, K.; Yoon, E.S. Integration of CCS, emissions trading and volatilities of fuel prices into sustainable energy planning and its robust optimization. Renew. Sustain. Energy Rev. 2011, 15, 665-672. [CrossRef]

33. De Rassenfosse, G. How SMEs exploit their intellectual property assets: Evidence from survey data. Small Bus. Econ. 2012, 39, 437-452. [CrossRef]

34. Bernd, F.; Holger, E.; Jens, L.; Martin, K. Patent portfolio analysis as a useful tool for identifying R\&D and business opportunities-An empirical application in the nutrition and health industry. World Patent Inf. 2006, 28, 215-225.

35. Stephens, J.C.; Jiusto, S. Assessing innovation in emerging energy technologies: Socio-technical dynamics of carbon capture and storage (CCS) and enhanced geothermal systems (EGS) in the USA. Energy Policy 2010, 38, 2020-2031. [CrossRef]

36. Middleton, R.S.; Bielicki, J.M. A comprehensive carbon capture and storage infrastructure model. Energy Proced. 2009, 1, 1611-1616. [CrossRef]

37. Li, Z.; Meng, F.; Cao, X. The evaluation method research of patent value based on the four factors. J. Intell. 2010, 29, 87-90.

38. Tong, X.; Frame, J.D. Measuring national technological performance with patent claims data. Res. Policy 2004, 23, 133-141. [CrossRef]

39. Jo, L.; Schankerman, M. Characteristics of Patent Litigation: A Window on Competition. Rand J. Econ. 2001, 32, 129-151.

40. Harhoff, D. Patent Quality and Examination in Europe. Am. Econ. Rev. 2016, 106, 193-197. [CrossRef]

41. Administrative Fee Schedules of SIPO. Available online: http:/ /www.sipo.gov.cn/zhfwpt/zlsqzn/zlsqfy / gjzscqjsfgs.pdf (accessed on 29 October 2017).

42. Chen, H.; Han, L. Indicators for patent quality and their effectiveness: A case study on machine tools patents issued by SIPO. Sci. Res. Manag. 2013, 34, 93-101.

43. Matzakos, A.N.; Wellington, S.L.; Mikus, T.; Ward, J.M. Integrated Flameless Distributed Combustion/Steam Reforming Membrane Reactor for Hydrogen Production and Use Thereof in Zero Emissions Hybrid Power System. US6821501, 23 November 2004.

44. Hsu, M.S. Zero/Low Discharge and Co-Production Type Energy Supply Station. CN100449841C, 7 January 2009.

45. INNOGRAPHY, Inc. Configurable Patent Strength Calculator. US2015/0331585A1, 19 November 2015.

46. Chang, Y.; Yang, W.G.; Lai, K.K. Valuable patent or not? Depends on the combination of internal patent family and external citation. Technol. Manag. Glob. Econ. Growth 2010, 39, 1-6.

47. Breitzman, A.; Thomas, P. The Emerging Clusters Model: A tool for identifying emerging technologies across multiple patent systems. Res. Policy 2015, 44, 195-205. [CrossRef]

48. OECD. OECD Patent Statistics Manual; OECD Publishing: Paris, France, 2009.

49. Harhoff, D.; Scherer, F.M.; Vopel, K. Citations, family size, opposition and the value of patent rights. Res. Policy 2003, 32, 1343-1363. [CrossRef]

50. Harhoff, D.; Narin, F.; Scherer, F.M.; Vopel, K. Citation Frequency and the Value of Patented Inventions. Rev. Econ. Stat. 1999, 81, 511-515. [CrossRef]

51. Viteri, F.; Taylor, J.P.; Brandt, H.; Anderson, R.E. Hydrocarbon Combustion Power Generation System with $\mathrm{CO}_{2}$ Sequestration. US6389814 B2, 21 May 2002.

52. Liu, Y.; Shao, Y.; Wang, W.; Liu, K. Equipment and Method for Extracting Biologically Active Ingredients from Subcritical Fluid. CN101905091A, 8 December 2010.

53. INNOGRAPHY. PatentStrength: Patent Value. Available online: https://www.innography.com/whyinnography/patentstrength (accessed on 29 November 2017).

54. Fradette, S.; Gingras, J.; Voyer, N.; Carley, J.; Kelly, G.R.; Ceperkovic, O. Process for $\mathrm{CO}_{2}$ Capture Using Micro-Particles Comprising Biocatalysts. US8846377, 30 September 2014.

55. Andrus, H.E.; Mccartney, M.S. Hot Solids Gasifier with $\mathrm{CO}_{2}$ Removal and Hydrogen Production. CN1795257, 28 June 2006. 
56. Qiu, H.; Chen, J. A study on the technology environment of Carbon Capture and Storage in US and its enlightenments based on PEST model. J. Intell. 2014, 33, 116-122.

57. Figueroa, J.D.; Fout, T.; Plasynski, S.I.; Srivastava, R.D. Advances in CO capture technology-The U.S. Department of Energy's Carbon Sequestration Program. Int. J. Greenh. Gas Control 2008, 2, 9-20. [CrossRef]

58. International Energy Agency. Sectoral Approaches in Electricity: Building Bridges to Safe Climate. Available online: https:/ / www.iea.org/publications / freepublications/publication/sectoral2009.pdf (accessed on 21 February 2018).

59. Duan, H.X. The public perspective of carbon capture and storage for $\mathrm{CO}_{2}$ emission reductions in China. Energy Policy 2010, 38, 5281-5289. [CrossRef]

60. Markewitz, P. Worldwide innovations in the development of carbon capture technologies and the utilization of $\mathrm{CO}_{2}$. Energy Environ. Sci. 2012, 5, 7281-7305. [CrossRef]

61. International Energy Agency. Carbon Capture and Storage: The Solution for Deep Emissions Reductions; OECD/IEA: Paris, France, 2015; Available online: http://www.iea.org/publications/freepublications / publication/CarbonCaptureandStorageThesolutionfordeepemissionsreductions.pdf (accessed on 24 February 2018).

62. Zhang, J. Carbon Capture, Utilization and Storage (CCUS) Technology Development in China. Available online: https://www.iea.org/media/workshops/2011/wpffbeijing/08_Zhang.pdf (accessed on 24 February 2018).

63. Alessandro, F.; Francesco, P.; Aliki, G.; Evangelos, T. Analysis of the European CCS research and innovation landscape. Energy Proced. 2017, 114, 7651-7658.

64. Du, X. CCUS Technology Policy Analyses and Management Researches under the Background of Energy Conservation and Emission Reduction. Master's Thesis, Shanxi University, Xi'an, China, 2016.

65. Choi, J.; Jun, S.; Park, S. A Patent Analysis for Sustainable Technology Management. Sustainability 2016, 8, 688. [CrossRef]

66. Uhm, D.; Ryu, J.B.; Jun, S. An Interval Estimation Method of Patent Keyword Data for Sustainable Technology Forecasting. Sustainability 2017, 9, 2025. [CrossRef]

67. Han, J.; Han, J.; Han, J. Technology Commercialization through Sustainable Knowledge Sharing from University-Industry Collaborations, with a Focus on Patent Propensity. Sustainability 2017, 9, 1808. [CrossRef]

68. Kim, J.; Lee, J.; Kim, G.; Park, S.; Jang, D. A Hybrid Method of Analyzing Patents for Sustainable Technology Management in Humanoid Robot Industry. Sustainability 2016, 8, 474. [CrossRef]

69. Blind, K.; Edler, J.; Frietsch, R.; Schmoch, U. Motives to patent: Empirical evidence from Germany. Res. Policy 2006, 35, 655-672. [CrossRef]

70. Nicola, B.; Rosa, G.; Maurizio, S. To patent or not to patent? A survey of Italian inventors on motivations, incentives and obstacles to university patenting. Scientometrics 2007, 70, 333-354.

71. Hu, K.; Chen, R.; Ji, J. Patent Lives and Commercial Motives of Chinese Academic Patents. J. Mod. Opt. 2017, $37,144-150$.

(C) 2018 by the authors. Licensee MDPI, Basel, Switzerland. This article is an open access article distributed under the terms and conditions of the Creative Commons Attribution (CC BY) license (http:// creativecommons.org/licenses/by/4.0/). 